\title{
Effect of Addition of Graphene and Carbon Nanotubes on Flexural Strength of Polymethylmethacrylate- A Comparative In-Vitro Study
}

\author{
Modhupa Ghosh ${ }^{1}$, Shilpa Shetty ${ }^{2}$ \\ ${ }^{1}$ Department of Prosthodontics, Maulana Azad Institute of Dental Sciences, New Delhi, India. ${ }^{2}$ Department of \\ Prosthodontics, Vokkaligara Sangha Dental College and Hospitals, Bangalore, Karnataka, India.
}

\section{ABSTRACT}

\section{BACKGROUND}

Heat polymerized denture base resins are a popular choice in prosthodontics for fabrication of partial or complete dentures, cranioplasts, hybrid implant prosthesis, and maxillofacial prosthetics. The wide utility of these materials can be attributed to their favourable mechanical properties. Despite the popularity gained by them, clinicians often encounter suboptimal flexural strength resulting in frequent fracture of the fabricated prosthesis. The purpose of this study was to compare the flexural strength (FS) of Polymethylmethacrylate (PMMA) modified using micro-additions of Multi-Walled Carbon Nanotubes (MWCNT) and Graphene Oxide (GO) as fillers respectively with PMMA having no micro-additions.

\section{METHODS}

This is an in-vitro comparative study. Sixty samples of PMMA were divided in three groups of 20 each containing: Group 1: no micro additions (control group), Group 2: $0.5 \mathrm{wt} \%$ MWCNT in monomer of PMMA resin, Group 3: $0.5 \mathrm{wt} \%$ GO in monomer of PMMA resin. MWCNT and Graphene oxide were dispersed in Methylmethacrylate (monomer) respectively by ultrasonic agitation. Monomer and polymer were mixed in the ratio of 1:3. The samples were heat polymerised. Finished samples were subjected to 3-point bending test for checking their flexural strength. The results were statistically compared using one-way ANOVA followed by post hoc Bonferroni corrected paired T test for inter-group comparisons.

\section{RESULTS}

The highest mean Flexural Strength of 36.5 MPa was recorded in Group 2 (MWCNT) followed by $31.55 \mathrm{MPa}$ in Group 1 (control) and the least 29.72 MPa in Group 3 (Graphene Oxide) respectively. Intergroup comparisons revealed significant difference between Group 1 (control) \& Group 2 (MWCNT) with "p=0.011" and between Group 2 (MWCNT) \& Group 3 (Graphene Oxide) with "p<0.001". However, no significant difference was found between Group 1 (control) and Group 3 (Graphene Oxide) with " $\mathrm{p}=0.803$ ".

\section{CONCLUSIONS}

The addition of 0.5 wt\% MWCNT to PMMA is an easy, effective and economical step towards increasing the flexural strength and thus, decreasing the incidence of prosthesis fracture, when compared to $0.5 \mathrm{wt} \%$ graphene oxide or no micro additions.

\section{KEY WORDS}

Carbon Nanotubes, Graphene, Polymethylmethacrylate, Flexural Strength
Corresponding Author: Dr. Modhupa Ghosh, Department of Prosthodontics, Crown and Bridge, Maulana Azad Institute of Dental Sciences, Mamc Complex, Bahadur Shah Zafar Marg, New Delhi-110002, India.

E-mail: modhupaghosh@gmail.com

DOI: $10.14260 /$ jemds/2020/326

Financial or Other Competing Interests: None.

How to Cite This Article:

Ghosh M, Shetty S. Effect of addition of graphene and carbon nanotubes on flexural strength of polymethylmethacrylate- a comparative in-vitro study. J. Evolution Med. Dent. Sci. 2020;9(18):1494-1499, DOI: 10.14260/jemds/2020/326

Submission 04-03-2020,

Peer Review 17-04-2020,

Acceptance 23-04-2020,

Published 04-05-2020.

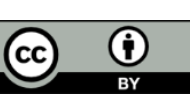




\section{BACKGROUND}

The clinician's choice of material for various prosthesis fabrication has been heat polymerized polymethylmethacrylate (PMMA), ever since its introduction in 1937 by Dr Walter Wright and Vernon brothers. The superior aesthetics, accuracy of fit, good oral stability, ease of manipulation and processing have been its favourable attributes. ${ }^{1}$ These properties have made this material a popular choice for fabrication of dentures, maxillofacial prosthesis, orthodontic appliances, cranioplasts, and hybrid implant prosthesis. Regardless of these advantages, the versatility of PMMA has been marred by reduced flexural strength, which is the mechanical property that helps a prosthesis endure fracture due to fatigue failure. This can be attributed to cyclic deformation of the base during function, caused by repeated application of masticatory forces or extraoral high impact force associated with accidental dropping of the prosthesis. Approximately $70 \%$ of dentures have been reported to be broken within 3 years of fabrication, with $29 \%$ incidence of maxillary midline fractures. ${ }^{2}$

In order to improve the flexural strength of PMMA, reinforcements by incorporation of various additives to the polymer like glass fibre, metal wires, carbon fibres, metal fillers have been tried in the past. ${ }^{3}$ The ultimate goal has been to develop a denture base with better mechanical properties, ease of processing, acceptable aesthetics and biocompatibility. Carbon nanotubes (CNTs) are nano-materials with a high potential of biological applications due to their enhanced mechanical, chemical and physical characteristics. ${ }^{4}$ They possess a hollow cylindrical shape with the walls being composed of hexagonal carbon rings. ${ }^{5,6}$ These nanotubes are known to exist in 2 forms, single walled carbon nanotubes (SWCNT) that have the basic cylindrical structure and multiwalled carbon nanotubes (MWCNT) that contain multiple (approximately 50) coaxial cylinders. ${ }^{7,8}$ The type of CNT used, the homogeneity of its dispersion, weight percentage (wt\%), alignment of the nanotubes and the polymer matrix are basic tenets of its augmented properties. ${ }^{9}$ The incorporation of CNT in PMMA has also been found to prevent microbial adhesion. ${ }^{10}$

Graphene, is a 2- dimensional carbon nanofiller with a 1 atom thick planar sheet of $\mathrm{sp}^{2}$ bonded carbon atoms arranged in a honeycomb crystal lattice. ${ }^{11,12}$ Its high surface area, tensile strength, good thermal and electrical conductivity, flexibility, and low coefficient of thermal expansion impart it a better outcome than other conventional nanofillers. ${ }^{13}$ Graphene, considered as the thinnest material, attributes its enhanced features to its rough surface texture, increased surface area and its 2 dimensional planar geometry. ${ }^{14}$ Graphene in its pristine form is found to be incompatible and lacks homogeneity. Thus, graphene oxide, the surface modification of graphene to enhance its matrix compatibility is favoured. ${ }^{15}$

Despite the improved structural design inherent in MWCNT and Graphene there is very limited literature available regarding the use of these nanofillers in heat polymerized PMMA, including their effect on various mechanical properties of PMMA. In the current era of dentistry, there is increased dependence on high flexural strength PMMA in several prosthesis fabrication. This mandates a search for a suitable nanofiller that can provide the most optimal outcome, in terms of increased flexural strength without compromising the remaining physical and mechanical properties. This study aimed to compare the flexural strength of Polymethylmethacrylate (PMMA) having microadditions of Multiwalled carbon nanotubes (MWCNT) and Graphene Oxide (GO) as fillers respectively with PMMA having no microadditions.

\section{METHODS}

Statistical analysis determined a sample size of 60 for a significant study. The specimens were divided in 3 groups of 20 each containing-

Group 1 : No micro additions (control group)

Group 2: Multiwalled Carbon Nanotubes 0.5 wt. \% in monomer of PMMA resin

Group 3 : Graphene 0xide 0.5 wt. \% in monomer of PMMA resin

Multiwalled Carbon Nanotubes (Adnano technology, India) having a diameter of $16-20 \mathrm{~nm}$, length $20 \mu \mathrm{m}$, and purity $>97 \%$ were utilized in Group 2. Simultaneously, for Group 3, Graphene Oxide having diameter $0.5 \mu \mathrm{m}, \mathrm{O}_{2}$ content $<20 \%$, purity $>98 \%$, and thickness 0.8-1.6 nm (Adnano technology, India) was used. An electronic precision balance (Shimadzu, Japan) was used to weigh $0.5 \mathrm{~g}$ MWCNT and Graphene Oxide. For the preparation of $0.5 \mathrm{wt} \%$ solutions of Group 2 and Group 3, $0.5 \mathrm{~g}$ of MWCNT and Graphene Oxide were added to $106 \mathrm{ml}$ (99.5 wt\%) of Methylmethacrylate monomer (Acralyn $\mathrm{H}$, India) respectively. To overcome the settling tendency of both the nanofillers, the solutions were subjected to agitation in an ultrasonic unit (the Science House, Chennai) of $400 \mathrm{~W}$ and 150 $\mathrm{KHz}$ power for 15 minutes to ensure homogenous dispersion (Fig. 1).

60 templates of dimensions $65 \mathrm{~mm} \mathrm{(l)} \times 10 \mathrm{~mm}(\mathrm{~b}) \times 3 \mathrm{~mm}$ $(\mathrm{t})$ were fabricated according to ADA specification $12^{16}$ using modelling wax (DPI Modelling wax, Dental products of India). They were invested in Type II dental gypsum (Kaldent; Kalabhai Karson Pvt Ltd) followed by dewaxing and subsequent obtainment of the desired moulds (Fig.2).

Monomer containing MWCNT (Group 2) and Graphene Oxide (Group 3) fillers respectively were mixed with polymethylmethacrylate polymer [Acralyn $\mathrm{H}$, Asian acrylates] in standard 1:3 ratio, while monomer with no micro additions served as the control group (Group 1). The mixed monomer and polymer were packed in dough stage in the pre-formed mould cavity followed by bench curing for 1 hour. A long polymerization cycle was followed. The flasks were heated at $65^{\circ} \mathrm{C}$ for 90 minutes, followed by heating at $100^{\circ} \mathrm{C}$ for 1 hour. Subsequent bench cooling was done for 30 minutes followed by deflasking (Fig.2). The polymerized samples were retrieved, finished, and polished using acrylic trimming bur and 120 grit and 240 grit sandpaper. Pumice and polishing cake were used for the final finish (Fig. 3). The samples were kept in water at $37^{\circ} \mathrm{C}$ for 2 weeks, until fully saturated, to simulate the oral as well as the storage conditions.

Universal testing machine [MultiTest 10-i, MecMesin] was used for checking the flexural strength. A 3-point bending test was performed following the ISO 1567 specifications for denture base polymers. ${ }^{17}$ Specimens were placed in a test rig with vertical supports $50 \mathrm{~mm}$ apart, with the plunger tip being 
$3.2 \mathrm{~mm}$ in diameter. A force was applied using a Mecmesin Multi Test 10-i System with Win Test software and a 500-lbf load cell at a crosshead speed of $5 \mathrm{~mm} / \mathrm{min}$ (Fig. 4). The fracture force $(\mathrm{F})$ was recorded in newtons $(\mathrm{N})$ and the flexural strength (FS) in MPa was calculated by applying the formula: $\mathrm{FS}=3 \mathrm{PL} / 2 \mathrm{bd}^{2}$, where "P" was maximum load, "L" was span length, "b" was specimen width, and " $d$ " was specimen thickness.

The data (FS) was collected for each group and subjected to inferential statistical analysis. The results were statistically compared using one-way ANOVA followed by post hoc Bonferroni corrected paired $\mathrm{T}$ test for inter-group comparisons.

\section{RESULTS}

The null hypothesis stating there was no significant difference in the mean flexural strength of Group 1 (PMMA having no micro additions), Group 2 (PMMA having 0.5 wt\% MWCNT) and Group 3 (PMMA having 0.5 wt $\%$ Graphene oxide) was rejected.

Graph 1, Graph 2 and Graph 3 depict the flexural strength values of the three groups, post subjection to 3-point bending test. The highest mean Flexural Strength of $36.5 \mathrm{MPa}$ was recorded in Group 2 (MWCNT) followed by $31.55 \mathrm{MPa}$ in Group 1 (control) and the least $29.72 \mathrm{MPa}$ in Group 3 (Graphene oxide) respectively (Table 1). On applying one-way ANOVA, the difference in mean flexural strength recorded among the groups was found to be statistically significant with "p" value $=0.000348\left(<0.001^{*}\right)$ (Table 2$)$.

To determine the difference between the 3 study groups, inter-group comparisons were carried out using Bonferroni post-hoc paired t- test corrections (Table 3). The difference in mean Flexural strength recorded was found to be statistically significant between Group 1 (control) \& Group 2 (MWCNT) with "p=0.011" as well as between Group 2 (MWCNT) \& Group 3 (Graphene Oxide) with " $p<0.001$ ". However, no significant difference in the flexural strengths could be discerned between Group 1 (control) and Group 3(Graphene Oxide) having a "p" value of $0.803(\mathrm{p}>0.05)$.

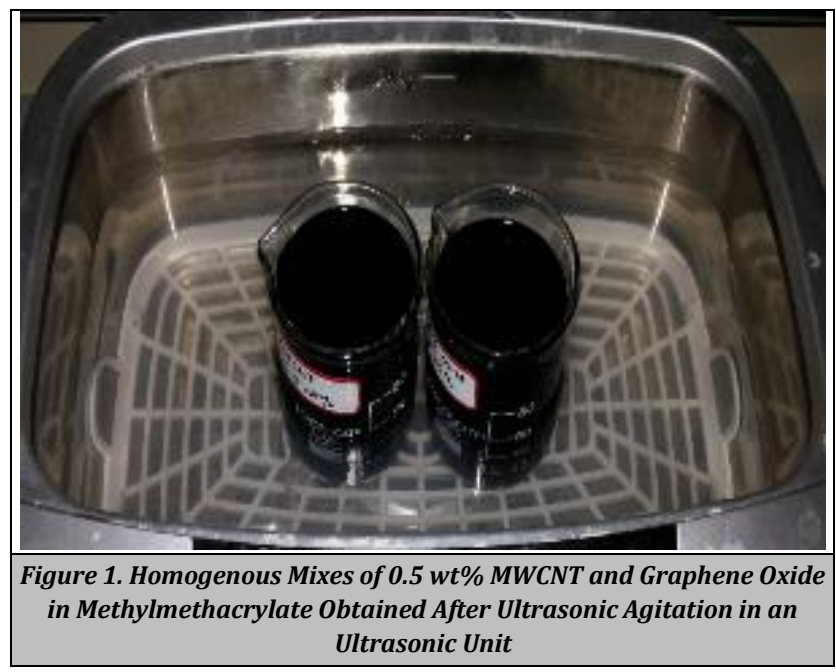

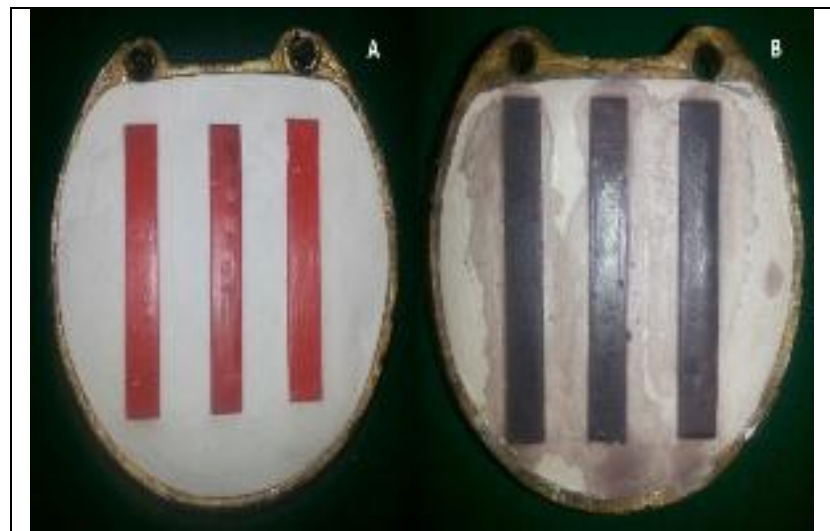

Figure 2. a) Wax Strip Templates of Dimensions $65 \mathrm{~mm}$ (I) $\times 10 \mathrm{~mm}$ (b) $\times 3 \mathrm{~mm}(\mathrm{t})$ invested in Type II Dental Gypsum b) Samples obtained Post-Acrylization

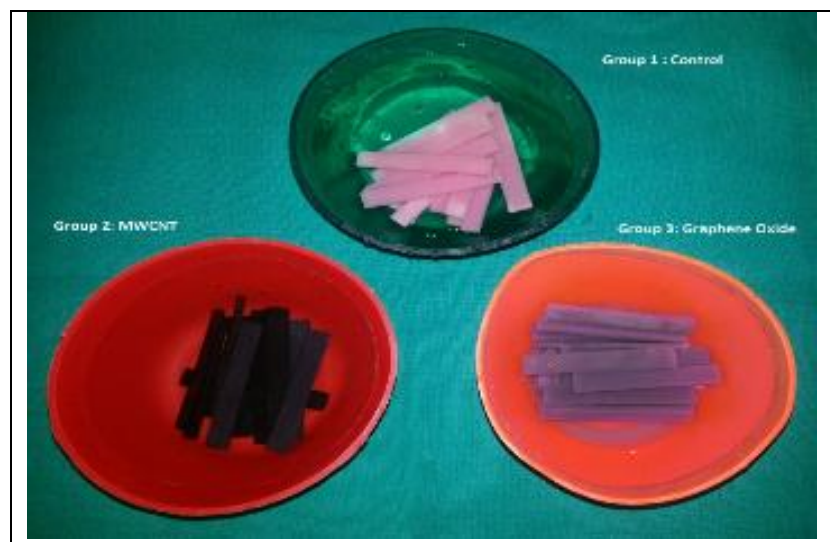

Figure 3. Finished and Polished Test Samples of Group 1: Control (Pink), Group 2: MWCNT (Black), Group 3: Graphene Oxide (Purplish Black)

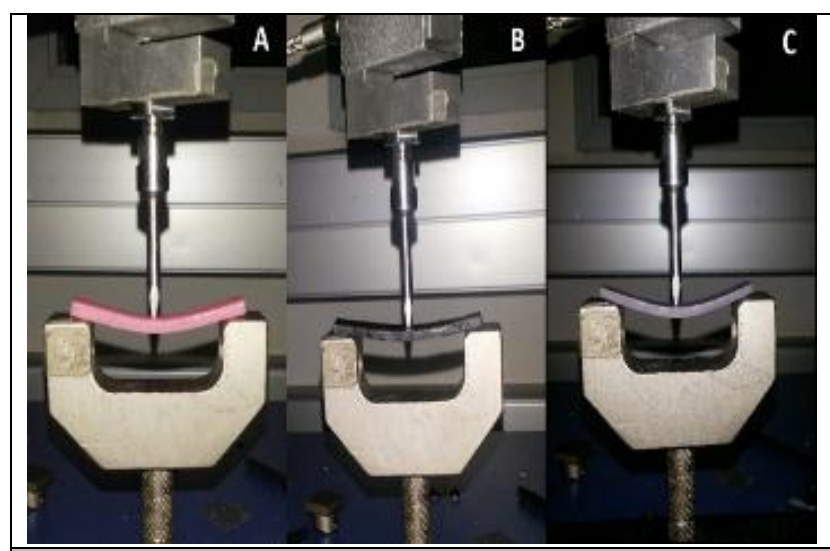

Figure 4. Samples of All 3 Test Groups A) Control B) 0.5 wt\% MWCNT and C) $0.5 w$ t\% Graphene Oxide Subjected to 3-Point Bending Test in Universal Testing Machine

\begin{tabular}{|c|c|c|c|c|c|c|c|}
\hline 总 & $\ddot{\Xi}$ & 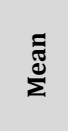 & $\begin{array}{l}\text { ê } \\
\text { a }\end{array}$ & 䍘 & 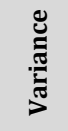 & $\stackrel{\Xi}{\Xi}$ & 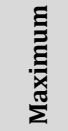 \\
\hline $\begin{array}{c}\text { Group 1 } \\
\text { (Control) }\end{array}$ & 20 & 31.55 & \pm 6.2230 & 1.391 & 38.72 & 21.54 & 42.88 \\
\hline $\begin{array}{c}\text { Group } 2 \\
\text { (MWCNT) }\end{array}$ & 20 & 36.50 & \pm 5.0517 & 1.129 & 25.52 & 27.72 & 45.03 \\
\hline $\begin{array}{l}\text { Group } 3 \\
\text { (Graphene } \\
\text { Oxide) }\end{array}$ & 20 & 29.72 & \pm 4.0029 & 0.895 & 16.02 & 23.32 & 39.69 \\
\hline \multicolumn{8}{|c|}{ Table 1. Mean Flexural Strength of the 3 Groups } \\
\hline
\end{tabular}



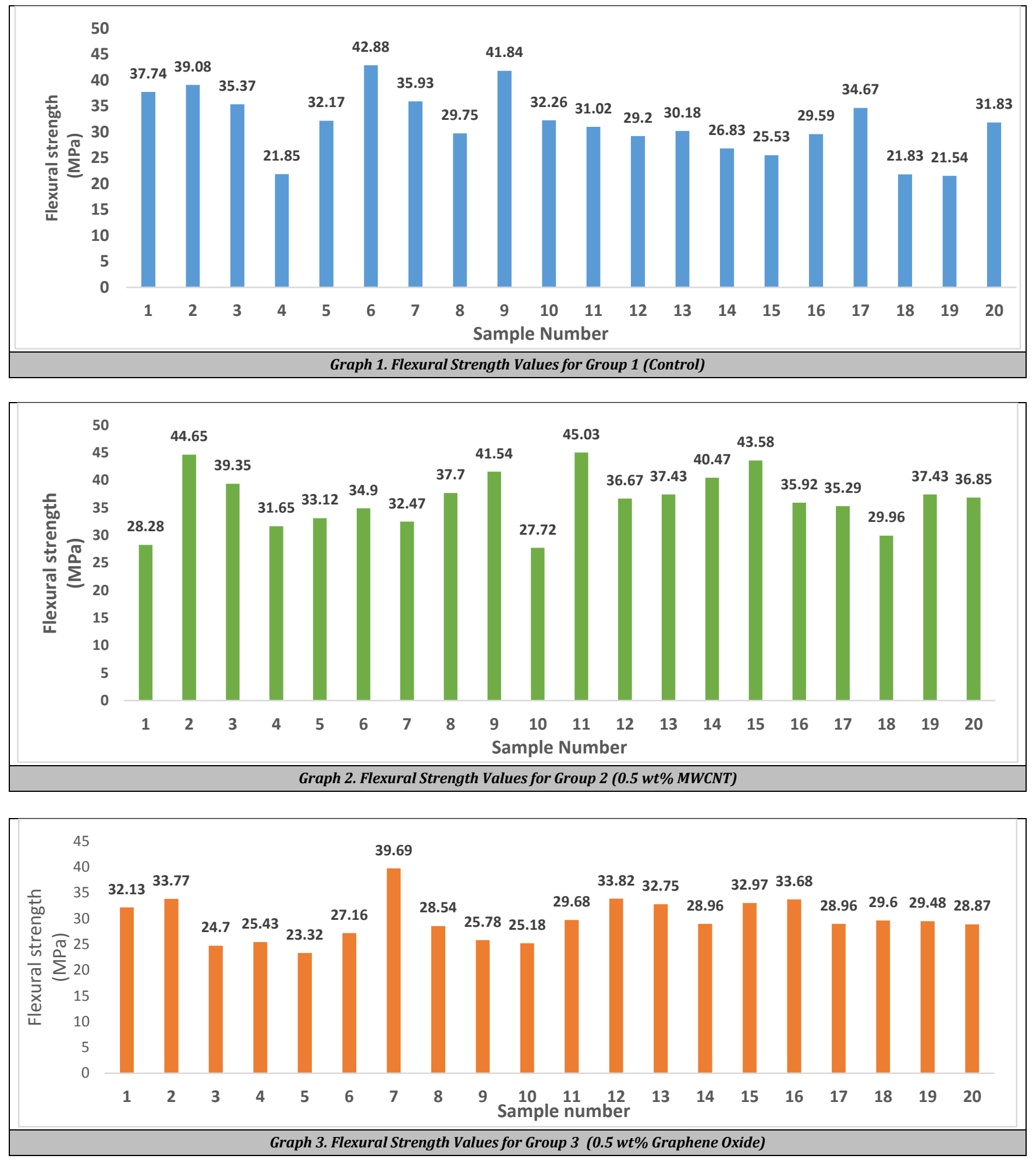

\begin{tabular}{|ccccccc|}
\hline Source of Variation & SS & Df & MS & F & P-Value & F crit \\
Between Groups & 491.62 & 2 & 245.8107 & 9.186878 & $0.000348 * 3.158843$ \\
Within Groups & 1525.13 & 57 & 26.75672 & & & \\
Total & 2016.75 & 59 & & & \\
\hline \multicolumn{7}{|c|}{ Table 2. One-Way ANOVA Summary for the 3 Test Groups } \\
\hline *denotes significant difference (p<0.05) \\
\hline
\end{tabular}

\begin{tabular}{|c|c|c|c|c|c|}
\hline \multirow{2}{*}{$\begin{array}{c}\text { (I) } \\
\text { Group }\end{array}$} & \multirow[b]{2}{*}{$\begin{array}{c}\text { (J) } \\
\text { Group }\end{array}$} & \multirow{2}{*}{$\begin{array}{c}\text { Mean } \\
\text { Difference } \\
\text { (I-J) }\end{array}$} & \multirow[b]{2}{*}{$\begin{array}{c}\text { P- } \\
\text { Value }\end{array}$} & \multicolumn{2}{|c|}{$95 \%$ CI } \\
\hline & & & & $\begin{array}{l}\text { Lower } \\
\text { Bound }\end{array}$ & $\begin{array}{l}\text { Upper } \\
\text { Bound }\end{array}$ \\
\hline Control & MWCNT & -4.946 & $0.011^{*}$ & -8.981 & -0.911 \\
\hline MWCNT & Graphene & $\begin{array}{l}1.831 \\
6.777\end{array}$ & $\begin{array}{c}0.803 \\
<0.001 *\end{array}$ & $\begin{array}{l}-2.204 \\
2.742\end{array}$ & $\begin{array}{c}5.866 \\
10.812\end{array}$ \\
\hline \multicolumn{6}{|c|}{ Table 3. Inter Group Comparisons Using Post-Hoc } \\
\hline
\end{tabular}

\section{DISCUSSION}

This study assessed the effect on the flexural strength of PMMA on incorporation of multiwalled carbon nanotubes and graphene oxide respectively. MWCNT were chosen because they are considered as desirable particles to modify material properties of polymer due to their high mechanical strength. ${ }^{18}$ Graphene was used in the form of graphene oxide as it is hydrophilic in nature and has stable dispersion. ${ }^{19}$

The inclusion of $0.5 \mathrm{wt} \%$ Multiwalled carbon nanotubes (MWCNT) and Graphene Oxide was decided as the chosen 
composition based on an assessment of previous studies which concluded that PMMA containing MWCNT 0.5\% and 1\% had better performance than the control group containing no MWCNT. The same however was not found to be true for 2 wt\% MWCNT due to its inadequate dispersion in PMMA matrix. ${ }^{20}$ Valles et al reported good dispersion of both fillers below 1 wt $\%$, while aggregation and a deterioration of the mechanical properties occurred at higher loadings. ${ }^{19}$

Table 1 depicts an increase in the mean flexural strength of PMMA samples containing $0.5 \mathrm{wt} \%$ MWCNT due to the effective bridging of the cracks by carbon nanotubes. The spatial hexagonal ring arrangement of the carbon in the nanotubes leads to a reduction in the segmental motion, thus, imparting strength and stability to the mix. ${ }^{4}$ The good dispersibility of these nanoparticles also enables them to enter between the chains of polymer and fill the spaces, this restricts the chain movement and increases strength and rigidity. ${ }^{9}$ The strong inter-atomic bonding between the carbon atoms leads to increased stability of the nanotubes. ${ }^{21}$

In contrast, 0.5 wt $\%$ Graphene oxide was observed to depict a reduction in flexural strength when compared to both the control as well as MWCNT (Table 1). This is possibly due to the aggregation of graphene sheets, leading them to behave like micrometer-size fillers with low surface area. Moreover, the agglomerates tend to develop steric obstacles, a hindrance occurring due to large size of groups within a molecule, preventing any further chemical reactions. This restricts the flow of polymer into the solution, resulting in the formation of voids. ${ }^{22}$ The voids introduce stress concentrations within the matrix making it susceptible to failure. The addition of graphene fillers has been reported to also decrease the flexural strength of laminated hybrid polymer composites as well epoxidized nanocomposites significantly.23,24 Future endeavours are needed in this direction to obtain a stable dispersion of this nanofiller within the matrix.

A limitation of both MWCNT as well as Graphene Oxide was the unaesthetic colour of the material, rendering its usage in the visible zone of the dentures problematic. Suitable colour modifications by addition of functional groups to MWCNTs and Graphene oxide need to be researched, which would impart the desired colour to the definitive prosthesis. Other alternatives can be to use Single walled carbon nanotubes (SWCNTs), which are transparent in nature or to use lesser quantity of MWCNTs in the PMMA matrix. ${ }^{20}$ However, till the resolution of this issue, PMMA reinforced with these nanofillers may be conveniently used in the less visible areas, such as the maxillary palate, mandibular lingual flange, acrylic backing in maxillofacial prosthesis and cranioplasts. ${ }^{25}$

The ease of availability, affordability, manipulation, biocompatibility and improved flexural strength favours the use of MWCNT into clinical applications of PMMA for prosthesis fabrication. The limitations can further be researched upon to increase its applicability in a multitude of situations.

\section{CONCLUSIONS}

In the current era of favouring digitally processed prepolymerized PMMA blocks, injection moulded systems, novel materials like PEEK, the use of compression moulded PMMA is often challenged due to its less than optimal mechanical properties. However, if micoadditions of nanoparticles to PMMA can enhance the mechanical properties and overcome its limitations, the lost glory of PMMA can be redeemed. A fractured prosthesis, irrespective of its design, is an inconvenience to both the dental surgeon and patient. The addition of $0.5 \mathrm{wt} \%$ multiwalled carbon nanotubes to PMMA is an easy, effective, and economical step, towards increasing the flexural strength, and thus, decreasing the incidence of prosthesis fractures. The limitations faced while reinforcing PMMA with graphene nanofillers need to be studied in detail so as to obtain a stable dispersion of the filler in the matrix. This in turn may help in utilizing the superior mechanical properties of graphene for the purpose of strengthening the denture base material.

\section{ACKNOWLEDGEMENT}

The authors thank Dr. C. L. Satish Babu for being the guiding force behind the inception and completion of this work.

\section{REFERENCES}

[1] Nejatian T, Johnson A, Van Noort R. Reinforcement of denture base resin. Advances in Science and Technology 2006;49:124-9.

[2] Darbar UR, Huggett R, Harrison A. Denture fracture-a survey. Br Dent J 1994;176(9):342-5.

[3] Alla R, Sajjan S, Alluri VR, et al. Influence of fiber reinforcement on the properties of denture base resins. J Biomat NanoBiotechnol 2013;4:91-7.

[4] Mars B, Andrews R, Pienkowski D. Multi wall carbon nanotubes enhance fatigue performance of physiologically maintained methyl methacrylate-styrene copolymer. Carbon 2007;45(10):2098-104.

[5] Bai J. Evidence of the reinforcement role of chemical vapour deposition multi-walled carbon nanotubes in a polymer matrix. Carbon 2003;41(6):1325-8.

[6] Kou W, Akasaka T, Watari F, et al. An in vitro evaluation of the biological effects of carbon nanotube-coated dental zirconia. ISRN Dent 2013;2013:296727.

[7] Sinha N, Yeow JTW. Carbon nanotube for biomedical application. IEEE Transaction Nanobioscience 2005;4(2):180-95.

[8] Vardharajula S, Ali SZ, Tiwari PM, et al. Functionalized carbon nanotubes: biomedical applications. International Journal of Nanomedicine 2012;7:5361-74.

[9] Ormsby R, McNally T, Mitchell C, et al. Incorporation of multiwalled carbon nanotubes to acrylic based bone cements: effects on mechanical and thermal properties. J Mech Behav Biomed Mater 2010;3(2):136-45.

[10] Kim KI, Kim DA, Patel KD, et al. Carbon nanotube incorporation in PMMA to prevent microbial adhesion. Sci Rep 2019;9(1):4921.

[11] Geim AK, MacDonald AH. Graphene: exploring carbon flatland. Physics Today 2007;60(8):35-41.

[12] Si Y, Samulski ET. Synthesis of water soluble graphene. Nano Lett 2008;8(6):1679-82. 
[13] Dreyer RD, Park S, Bielawski CW, et al. The chemistry of graphene oxide. Chem Soc Rev 2010;39(1):228-40.

[14] Rafiee MA, Rafiee J, Srivastava I, et al. Fracture and fatigue in graphene nanocomposites. Small 2010;6(2):179-83.

[15] Hummers Jr WS, Offeman RE. Preparation of graphitic oxide. J Am Chem Soc 1958;80(6):1339.

[16] John J, Gangadhar SA, Shah I. Flexural strength of heat polymerized polymethyl methacrylate denture resin reinforced with glass, aramid or nylon fibers. J Prosthet Dent 2001;86(4):424-7.

[17] International Organization for Standardization. Specification 1567: denture base polymers. $2^{\text {nd }}$ edn. Geneva: ISO, 1998.

[18] Bal S, Samal SS. Carbon nanotube reinforced polymer composites - a state of the art. Bull Mater Sci 2007;30(4):379-86.

[19] Valles C, Kinloch IA, Young RJ, et al. Graphene oxide and base washed graphene oxide as reinforcements in PMMA nanocomposites. Composi Sci Tech 2013;88:158-64.

[20] Wang R, Tao J, Yu B, et al. Characterization of multiwalled carbon nanotube-polymethyl methacrylate composite resins as denture base materials. J Prosthet Dent 2014;111(4):318-26.
[21] Collins PG, Avouris P. Nanotubes for electronics. Sci Am 2000;283(6):62-9.

[22] Shen MY, Chang TY, Hsieh TH, et al. Mechanical properties and tensile fatigue of graphene nanoplatelets reinforced polymer nanocomposites. Journal of Nanomaterials 2013;2013:565401.

[23] Gouda PS, Kulkarni R, Kurbet SN, et al. Effects of multi walled carbon nanotubes and graphene on the mechanical properties of hybrid polymer composites. Adv Mat Lett 2013;4:261-70.

[24] Chieng BW, Ibrahim NA, Yunus WM, et al. Graphene nanoplatelets as novel reinforcement filler in poly (lactic acid)/epoxidized palm oil green nanocomposites: mechanical properties. Int J Mol Sci 2012;13(9):1092034.

[25] Mahmood WS. The effect of incorporating carbon nanotubes on impact, transverse strength, hardness and roughness to high impact denture base material. J Bagh College Dentistry 2015;27(1):96-9. 